\title{
The Neuropathy of Charlevoix-Saguenay Ataxia: An Electrophysiological and Pathological Study
}

\author{
J.M. PEYRONNARD, L.CHARRON AND A.BARBEAU
}

SUMMARY: Two female patients aged 30 and 40 rears with the Charlevoix-Saguenay ataxia were studied. Both had absent sensory action potentials in upper and lower extremities but, unlike tipical cases of Friedreich's ataxia, they displayed a marked slowing of motor conduction velocities. Sural nerve biopsies taken from calf and ankle revealed a severe loss of large myelinated axons contrasting with a normal mielinated fiber density. Evidence for active axonal degeneration was scarce, with no indication of axonal regeneration.

RÉSUMÉ: Deux patientes âgées de 30 et 40 ans furent étudiées. Elles n'avaient aucun potentiel d'action sensitif enregistrable dans les membres supérieurs ou inférieurs mais différaient des cas typiques d'ataxie de Friedreich en raison d'un ralentissement très marqué des vitesses de conduction motrice. Les biopsies du nerf sural prélevées au mollet et à la cheville ont montré une perte sévère des axones myélinisés de gros calibre contrastant avec une densité normale de fibres myélinisées. Les signes de dégénérescence axonale active étaient extrêmement discrets sans
Teased myelinated fibers revealed an increased variability of internodal length but no evidence for myelin breakdown. These findings support, as a primary defect, a developmental abnormality of peripheral nerve, namely a lack of maturation of large myelinated axons and possibly a faulty myelination of nerve fibers. We think it is unlikely to represent a progressive axonal atrophic or dystrophic process, as suggested in Friedreich's ataxia.

évidence de régénérescence. Les études de fibres myélinisées isolées ont montré une variabilité anormale des distances internodales mais aucun signe de dégénérescence myélinique. Ces observations suggèrent l'existence d'une anomalie de développement des nerfs périphériques nommément un défaut de maturation des axones myélinisés de gros calibre et possiblement une mýélinisation défectueuse des fibres nerveuses. Nous considérons improbable qu'il s'agisse d'une atrophie ou d'une distrophie axonale progressive tel que suggéré dans l'ataxie de Friedreich.
From the Centre de Recherche en Sciences Neurologiques, Hôtel-Dieu Hospital and the Clinical Research Institute, Université de Montréal.

Reprint requests for this paper only to: $\mathrm{Dr}$. J. M Peyronnard, Centre de Recherche en Sciences Neurologiques, Département de Physiologie, Faculté de Médecine, Université de Montréal, Montréal, Québec. Canada H3C 3T8.

Reprint requests for the complete supplement on Friedreich's Ataxia. (Phase Two, Part Two) to: Dr André Barbeau. Clinical Research Institute of Montreal, 110 Pine Avenue West, Montreal, Quebec. Canada H2W IR7.

\section{INTRODUCTION}

This paper reports the electrophysiological and pathological abnormalities found in the peripheral nervous system of 2 patients presenting with the autosomal recessive spastic ataxia of Charlevoix-Saguenay (Bouchard et al., 1978).

\section{MATERIALS AND METHODS}

Two female patients aged 30 (case I) and 40 (case II) years, with the typical features of the disease, were studied.

\section{Electrophysiological techniques}

The technical details have been fully described in a previous paper (Peyronnard et al., 1976). Sensory action potentials (SAP) together with sural nerve action potentials (NAP) were recorded with surface electrodes. Motor conduction velocities (MCV) were determined in the median, ulnar, common peroneal, and posterior tibial nerves, using surface recording electrodes. Electromyographic studies (EMG) of the extensor digitorum brevis, tibialis anterior, and gastrocnemius muscles were done with concentric needle electrodes. Patients were tested in a warm room $\left(23^{\circ} \mathrm{C}\right)$. Records obtained from 10 normal subjects aged 25 to 35 years served as controls.

\section{Histological techniques}

Sural nerve biopsies were performed at the calf in case I and ankle in case II. In addition, a sample of the gastrocnemius muscle was obtained in case I. Control sural nerves from two normal subjects aged 33 and 35 years were taken at the calf (control I) and ankle (control II) respectively. Upon removal, nerve specimens were divided into three segments. The first was immersed for 2 hours in $2 \%$ 
TABLE 1

Electrophysiology

\begin{tabular}{l|ccc}
\hline & Case 1 & Case 2 & Controls \\
\hline $\begin{array}{l}\text { Sensory Conduction (M/sec) } \\
\text { Median }\end{array}$ & 0 & & \\
Ulnar & 0 & 0 & $55,8 \pm 5,0$ \\
$\quad$ Sural & 0 & 0 & $53,4 \pm 4,4$ \\
MOTOR CONDUCTION & & 0 & $48,9 \pm 4,4$ \\
Distal latency (msec) & & & \\
$\quad$ Median & 5,7 & 5,6 & $3,8 \pm 0,4$ \\
Ulnar & 3,4 & 4,2 & $3,4 \pm 0,4$ \\
$\quad$ Common peroneal & 10 & 9,4 & $4,8 \pm 1,0$ \\
$\quad$ Posterior tibial & - & 10,3 & $5,0 \pm 1,0$ \\
Conduction velocity $(M / \mathrm{sec})$ & & & \\
$\quad$ Median & 41,8 & 41,3 & $57,8 \pm 4,2$ \\
$\quad$ Ulnar & 39,4 & 44,6 & $59,7 \pm 5,3$ \\
$\quad$ Common peroneal & 22,3 & 30,2 & $49,0 \pm 4,6$ \\
$\quad$ Posterior tibial & - & 30,4 & $47,4 \pm 4,0$ \\
\hline
\end{tabular}

glutaraldehyde in $0.1 \mathrm{M}$ phosphate buffer, pH 7.4. Post-fixation in $1 \%$ osmic acid was followed by dehydration in alcohol and embedding in epoxy resin. For phase microscopy, semithin sections were cut and stained with paraphenylenediamine. Ultrathin sections were examined with a Philips electron microscope after staining with lead citrate. Quantitative studies of myelinated fibers (MF) were made from photomicrographs of nerve transverse sections enlarged to a final magnification of $x 1,000$. The number and size distribution of MF per nerve and per square millimeter of fascicular area were determined. The same parameters for unmyelinated fibers (UNF) were obtained from montage of nonoverlapping electron micrographs at a 10,000 magnification.

The second segment of the nerve was fixed in glutaraldehyde as already described. Post-fixation in 1\% osmic acid for 3 hours was followed by maceration in glycerol for 3 days. Single fibers were isolated under a dissecting microscope for measurement of internodal length and diameter. The remainder of the nerve was frozen for longitudinal sections and stained with the modified Gomori trichrome technique. Frozen sections of the muscles were stained with the following histochemical techniques: modified Gomori trichrome, hema- toxylinphloxine, succinic dehydrogenase (SDH), myofibrillar adenosine triphosphatase (ATPase) at $\mathrm{pH} 9.4$ and 4.4, Oil Red 0, and periodic acid Schiff (PAS).

\section{RESULTS}

\section{Electrophysiological studies}

The same abnormalities were noted in both patients. As shown in Table I, median and ulnar SAP and sural NAP were absent. MCV were reduced markedly in the lower limbs and to a lesser extent in the upper extremities. EMG of the extensor digitorum brevis

\section{CONTROL 2}

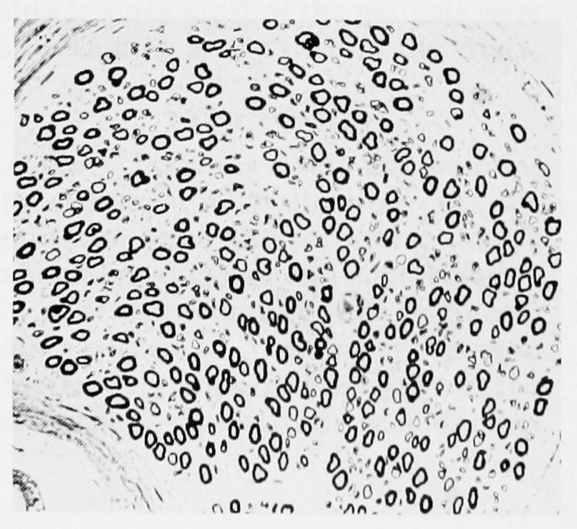

\section{SURAL NERVE}

Fig. I - Cross section of sural nerve fascicle, taken from ankle in case II and matched control. An obvious loss of large myelinated fibers can be seen (phase micrograph x 64). 


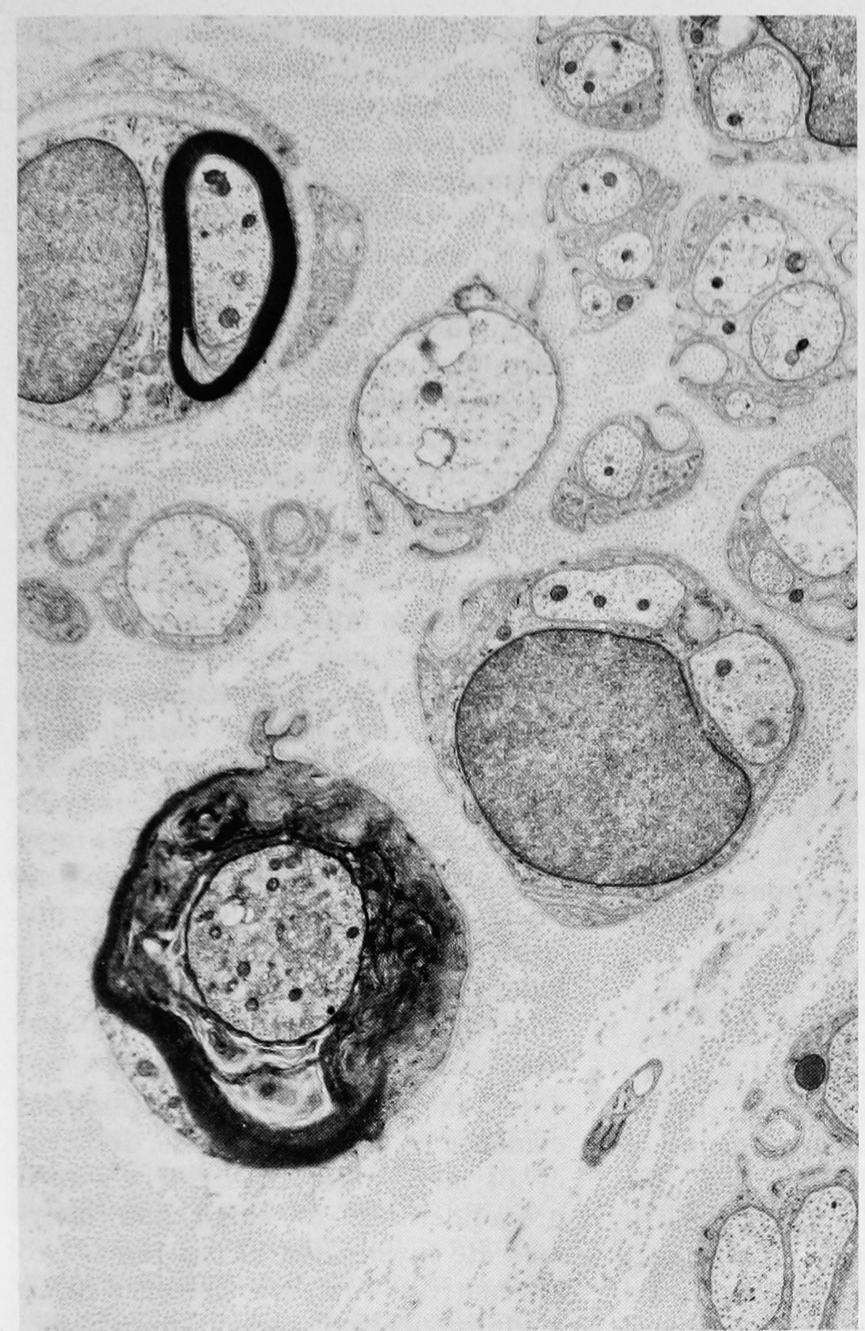

Fig. 2-Sural nerve biopsy from case II. A degenerated myelinated axon shows clumping of neurotubules and neurofilaments, accumulation of mitochondria and small vesicular bodies and degeneration of myelin (cross sectional electronmicrograph $\mathrm{x} 10,000)$

excessive layering of Schwann cell cytoplasm (Fig. 3). There was no evidence of regeneration of either myelinated or unmyelinated axons.

Teased nerve fiber studies. Single fibers were teased from the sural nerve of case II. The majority of fibers were of small and intermediate diameter. No fiber showed paranodal or internodal absence of myelin. Measurement of internodal distances and fiber diameters revealed in some fibers a higher than normal variability of internodal length (Fig. 4).

Quantitative results. The density of MF was $12,937 / \mathrm{mm}^{2}$ in case I and $8,960 / \mathrm{mm}^{2}$ in case II. The values are comparable to those obtained in control subjects $\left(8,960\right.$ and $7,572 / \mathrm{mm}^{2}$ for control I and control II, respectively). In spite of their normal density, the size distribution of $\mathrm{MF}$ was abnormal. As shown by the histograms (Fig. 5) most of the large myelinated fibers were absent. Fibers with a diameter greater than $8 \mu$ constituted $16.2 \%$ (case I) and $18.3 \%$ (case II) of all myelinated fibers, as compared with control values of $31 \%$ and $36 \%$ at calf and ankle respectively. The density of UNF was within normal range: $36,425 / \mathrm{mm}^{2}$ in case 1 and $42,529 / \mathrm{mm}^{2}$ in case II (Ochoa, 1969). No appreciable difference between patients and controls was noted in the size distribution histograms of UNF (Fig. 6).

\section{Muscle biopsy specimen}

In case I, where it was available, the muscle biopsy showed variations in fiber size, with mildly atrophic and hypertrophic fibers. ATPase and SDH reactions revealed moderate type grouping and hypertrophic fibers to be of type I. These observations are consistent with mild chronic denervation.

\section{DISCUSSION}

This report suggests that, besides distinct genetic and clinical features, patients with the autosomal recessive spastic ataxia of Charlevoix-Saguenay also have abnormalities of the peripheral nervous system at variance with those described in other forms of spino-cerebellar degeneration. 

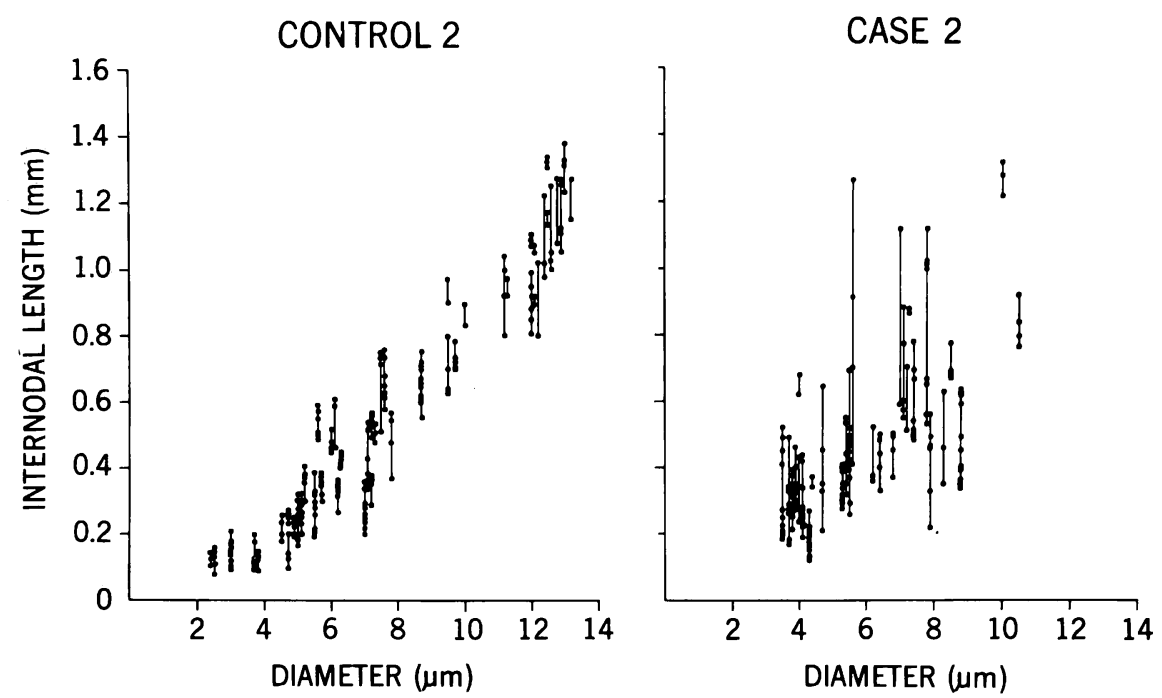

Fig. 4-Distribution of internodal length in single fibres. Lengths of internodes in individual fibers are plotted against diameters and joined by a vertical line.

From an electrophysiological standpoint, our patients show a marked impairment of sensory and motor functions which distinguishes them from patients with spastic ataxia of dominant or recessive inheritance in whom nerve conduction is normal (McLeod, 1976). Although they share a complete absence of sensory action potentials with patients suffering from Friedreich's ataxia, the marked reduction of motor conduction velocities found in our cases represents a distinctive feature, compared with the mild slowing observed in the typical form of Friedreich's ataxia (Preswick, 1968; Dyck and Lambert, 1968; McLeod, 1971; Oh and Hasley, 1973; Salisachs et al., 1975; Fiaschi et al., 1976; Peyronnard et al., 1976). Comparisons with other forms of spino-cerebellar degeneration is difficult, the literature being insufficient with the exception of a report (McLeod, 1976) describing mild impairment of sensory conduction in 2 patients with olivo-ponto-cerebellar degeneration of the Menzel type.

These electrophysiological abnormalities can be correlated with the pathological changes observed on sural nerve biopsies. In both patients, the most striking feature is a marked reduction in the number of large myelinated fibers. This finding has been reported by several authors in Friedreich's ataxia (Friedreich, 1863; Mott, 1907 Hughes et al., 1968; Dyck and Lambert, 1968; Dyck et al., 1971; McLeod, 1971) and explains the absence of sensory nerve action potentials. It has been attributed to a degeneration affecting, early in life, the large diameter myelinated axons. In Friedreich's ataxia, progression of the disease would lead to a loss of smaller axons and consequently to a marked reduction in fiber density as noted by Dyck et al. (1971) and McLeod (1971) in patients aged 17 to 25 . However, this mechanism does not seem to apply in our patients who still have, despite a disease which started in infancy, entirely normal myelinated fiber densities at age 30 and $\mathbf{4 0 .}$

In the absence of histological evidence of regeneration, the deficiency of large myelinated fibers with a preponderance of small and intermediate myelinated axons raises two alternatives: first, the presence of an atrophic, also called dystrophic,
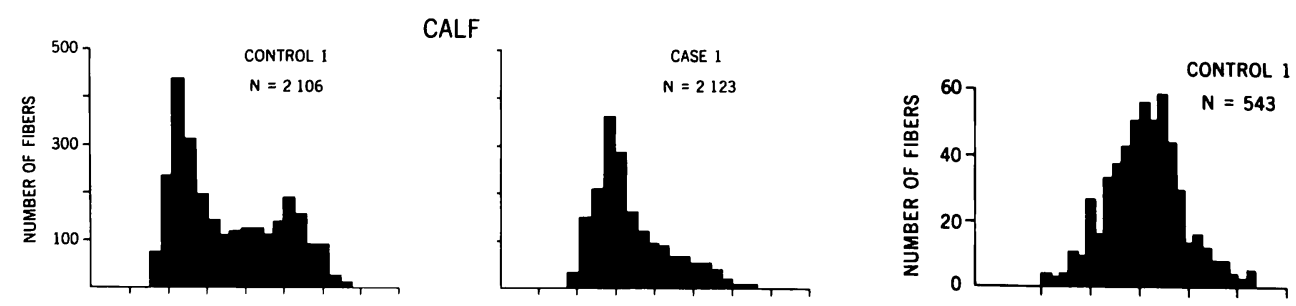

CALF
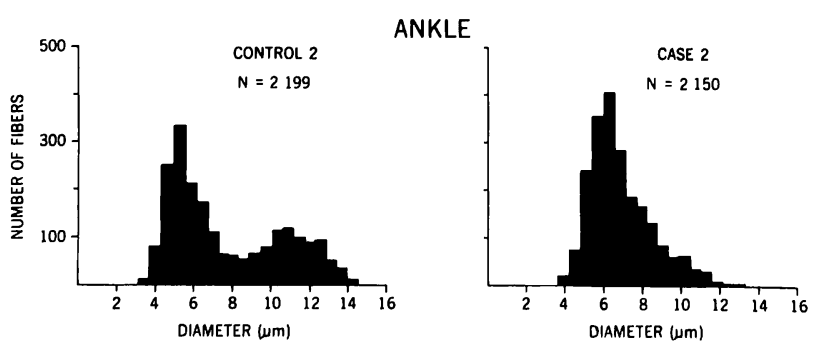

Fig. 5-Fiber-diameter histograms of myelinated fibers from patients and controls. Note markedly decreased number of myelinated fibers in both patients.
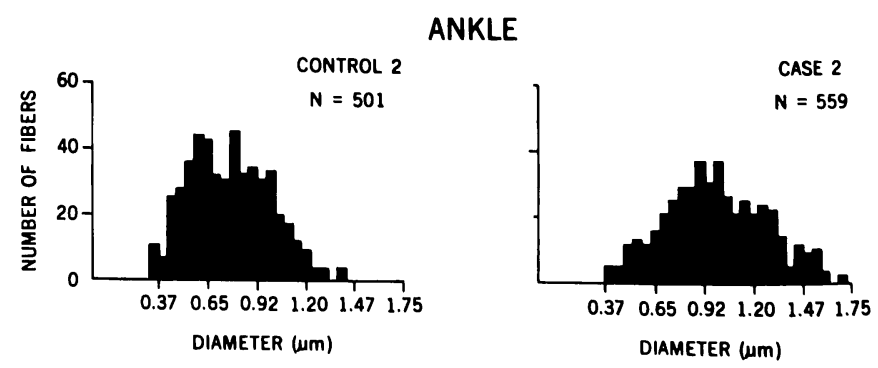

Fib. 6-Fiber-diameter histograms of unmyelinated fibers. No appreciable difference is noted between patients and controls. 
axonal process of slow progression (Greenfield, 1954; Dyck et al. 1971; Dyck and Ohta, 1975) in which large myelinated fibers shrink in diameter distally and so appear in smaller size categories; second, and this is our hypothesis, the existence of a developmental defect of the peripheral nervous system with lack of maturation of large myelinated fibers. In this instance one would expect, as is the case in our patients, the deficiency in the number of large myelinated axons to be of the same magnitude at proximal and distal nerve levels. This hypothesis should also be taken into consideration to explain the absence, in Friedreich's ataxia, of sensory action potentials in patients as young as 2 years of age (Dunn, 1973). Needless to say, a developmental abnormality does not exclude a superadded degenerative process of peripheral nerves, as documented in our patients by the presence of an occasional degenerating axon.

A developmental defect of myelination can also be raised on the basis of two observations: the existence on teased nerve fiber preparations of an increased variability of internodal distances along the same fiber, with no indication of active myelin breakdown, and the presence of a marked slowing of motor conduction velocities, seemingly out of proportion to what could be expected solely from a loss of large myelinated fibers, as in Friedreich's ataxia. It seems unlikely that these observations could represent merely demyelination secondary to axonal degeneration (Dyck and Lais, 1973), as changes suggestive of active axonal breakdown were very rare in our material.

In conclusion, we think that greater emphasis should be put on precise evaluation of peripheral nerve abnormalities, including morphometric studies, in order to better understand and distinguish the various pathophysiologic mechanisms underlying spino-cerebellar degenerations and related disorders.

\section{ACKNOWLEDGEMENTS}

This study was supported by grants from the Medical Research Council of Canada, the Foundation C.O Monat and the Association Canadienne de l'Ataxie de Friedreich.

The technical assistance of Mrs. J. Perreault and D. Guérette is acknowledged with gratitude.

\section{REFERENCES}

BOUCHARD, J. P., BARBEAU, A., BOUCHARD, R. and BOUCHARD, R. W. (1978). Autosomal recessive spastic ataxia of Charlevoix-Saguenay. Can. J. Neurol. Sci. 5, 61-69.

DUNN, H. G. (1973). Nerve conduction studies in children with Friedreich's ataxia and ataxia-telangiectasia. Develop. med. Child. Neur. 15, 324-337.

DYCK, P. J., LAMBERT, E. H. (1968). Lower motor and primary sensory neuron diseases with peroneal muscular atrophy. II. Neurologic, genetic, and electrophysiologic findings in various neuronal degenerations. Arch. Neurol. 18, 619-625.

DYCK, P. J., LAMBERT, E. H. and NICHOLS, P. C. (1971). Quantitative measurement of sensation related to compound action potential and number and sizes of myelinated and unmyelinated fibers of sural nerve in Health, Friedreich's ataxia, Hereditary Sensory Neuropathy and Tabes Dorsalis. In: Handbook of Electroencephalography and Clinical Neurophysiology, 9 . 83-118. Elsevier Publishing Co. Amsterdam.

DYCK, P. J. and LAIS, A. C. (1973). Evidence for segmental demyelination secondary to axonal degeneration in Friedreich's ataxia. In: Clinical studies in myology, Kakulas, B. A. (ed.) pp. 253-263, Excerpta Medica, Amsterdam.
DYCK, P. J. and OHTA, M. (1975). Neuronal atrophy and degeneration predominantly affecting peripheral sensory neurons. In: Peripheral neuropathy, vol. II, Dyck, P. J., Thomas, P. K., and Lambert, E. H. (eds.) pp. 79I-824, W. B. Saunders Co., Philadelphia.

FIASCHI, A., FERRARI, G. DE GRANDIS, D. and TOMELLERI, G. (1976). Aspetti electromiografici ed istologici in corso di malattia di Friedreich. Acta Neurologica (Napoli) 31, 162-169.

FRIEDREICH, N. (1863). Ueber degenerative atrophie der spinalen Hinterstránge. Virchows Arch. path. Anat. 27, 1-26.

GREENFIELD, J. G. (1954). The spinocerebellar degenerations. Blackwell Scientific Publications, Oxford.

HUGHES, J. T., BROWNELL, B., and HEWER, R. L. (1968). The peripheral sensory pathway in Friedreich's ataxia. Brain 91, 803-817.

McLEOD, J. G. (1971). An electrophysiological and pathological study of peripheral nerves in Friedreich's ataxia. J. Neurol. Sci. 12, 333349.

McLEOD, J. G. and MORGAN, J. A. (1976). Electrophysiological and pathological studies in spinocerebellar degenerations. Proc. Aust. Ass. Neurol. 13, 113-117.

MOTT, F. W. (1907). Case of Friedreich's disease, with autopsy and systematic microscopical examination of the nervous system. Arch. Neurol. Pathol. Lab. (Lond) 3, 180200.

OCHOA, J. and MAIR, W. G. P. (1969). The normal sural nerve in man. I- Ultrastructure and numbers of fibres and cells. Acta Neuropath. (Berl.) 13, 197-216.

OH, S. J. and HASLEY, J. H. (1973). Abnormality in nerve potentials in Friedreich's ataxia. Neurol. 23, 52-54.

PEYRONNARD, J. M., LAPOINTE, L., BOUCHARD, J. P., LAMONTAGNE, A., LEMIEUX, B. and BARBEAU, A. (1976). Nerve conduction studies and electromyography in Friedreich's ataxia. Can. J. Neurol. Sci. 3, 313-317.

PRESWICK, G. (1968). The neuropathy of Friedreich's ataxia. Proc. Aust. Assoc. Neurol. 5, 69-71.

SALISACHS, P., CODINA, M. and PRADAS, J. (1975). Motor conduction velocity in patients with Friedreich's ataxia. J. Neurol. Sci. 24, 331-337. 